\title{
Flouride Promotes Viability and Differentiation of Osteoblast-Like Saos-2 Cells Via BMP/Smads Signaling Pathway
}

\author{
Liangliang Huo $\cdot$ Kangkang Liu $\cdot$ Junrui Pei • \\ Yanmei Yang • Yan Ye • Yang Liu • Jing Sun • \\ Hepeng Han • Weimin Xu • Yanhui Gao
}

Received: 12 May 2013 / Accepted: 22 July 2013 / Published online: 7 August 2013

(C) The Author(s) 2013. This article is published with open access at Springerlink.com

\begin{abstract}
The BMP/Smad signaling pathway plays an important role in the viability and differentiation of osteoblast; however, it is not clear whether this pathway is involved in the fluoride-induced osteoblast differentiation. In this study, we investigated the role of BMP/Smad signaling pathway in fluoride-induced osteoblast-like Saos-2 cells differentiation. Cells were exposed to fluoride of different concentrations $(0$, $0.1,0.2,0.4,0.8$, and $1.6 \mathrm{mM}$ ), and cell proliferation was determined using WST assays. The expression of osteoblast marker genes such as osteocalcin (BGP) and bone alkaline phosphatase (BALP) were detected by qRT-PCR. We found that fluoride enhanced the proliferation of Saos- 2 cells in a dose-dependent manner and $0.2 \mathrm{mM}$ of fluoride resulted in a higher expression of osteoblast marker genes. In addition, immunofluorescence analysis showed that the promotion effects of $0.2 \mathrm{mM}$ of fluoride on Saos-2 cells differentiation were associated with the activation of the BMP/Smad pathway. Expression of phosphorylated Smad1/5(p-Smad1/5) was higher in cells exposed to $0.2 \mathrm{mM}$ of fluoride. Plasmid
\end{abstract}

\footnotetext{
L. Huo $\cdot$ W. Xu

Department of Endemic Diseases Control and Prevention, Hangzhou Center for Disease Control and Prevention, Hangzhou, Zhejiang, China

K. Liu

Jiangsu Institute of Parasitic Diseases, Wuxi, Jiangsu, China

J. Pei $\cdot$ Y. Ye $\cdot$ Y. Liu $\cdot$ J. Sun $\cdot$ H. Han $\cdot$ Y. Gao $(\bowtie)$ Center for Endemic Disease Control, Chinese Center for Disease Control and Prevention, Harbin Medical University, Key Lab of Etiology and Epidemiology, Education Bureau of Hei Long Jiang Province and Ministry of Health (23618104), 157 Baojian Road, Nangang District, Harbin 150081, Heilongjiang, China e-mail: gaoyh411@163.com

Y. Yang

Cancer Research Institute, Harbin Medical University, Harbin, Heilongjiang, China
}

expression vectors encoding the short hairpin RNA (shRNA) targeting Smad4 gene were used to block the $\mathrm{BMP} / \mathrm{Smad}$ pathway, which resulted in a significantly reduced expression of BGP and BALP as well as their corresponding mRNA. The mRNA levels after transfection remained low even in the presence of fluoride. The present results reveal that $\mathrm{BMP} /$ Smad signaling pathway was altered during the period of osteogenesis, and that the activities of $\mathrm{p}-\mathrm{Smad} 1 / 5$ were required for Saos- 2 cells viability and differentiation induced by fluoride.

Keywords Fluorine $\cdot$ Bone morphogenetic protein $\cdot$ Alkaline phosphatase $\cdot$ Osteocalcin $\cdot$ SMADs

\section{Introduction}

Fluoride is a common mineral found in soil, water, and various foods. As excessive and prolonged intake of fluoride can cause diseases such as dental fluorosis, skeletal fluorosis, and the weakening of bones, low doses of fluoride have been shown to reduce tooth decay and improve oral health without health risks. The action of fluoride on bone has been studied extensively, and the effects of fluoride on the physical properties of bone are well documented. As the dose of fluoride is certainly a factor in affecting bone quality and growth, recent studies have looked at how fluoride affects the bone signaling pathway, leading to changes in the bone [1-3].

The formation of bone and the development of the skeletal system require the coordinated activities of multiple signaling proteins, such as bone morphogenetic proteins (BMPs). BMPs belong to the biggest member of the transforming growth factor beta (TGF- $\beta$ ) family of growth and differentiation factors [4]. Like other members of the TGF- $\beta$ superfamily, BMPs exert their biological functions via interaction with two different types of serine/threonine kinase receptors-termed types I and 
II. Signals from the type I receptor, when phosphorylated by the type II receptor, are transmitted to the downstream substrates through various molecules, the most important among them being Drosophila mothers against decapentaplegic protein (Smads). Subsequent activation of target genes by Smads signaling is essential for bone development.

Smads are classified into three subgroups according to their functions: (1) pathway-restricted Smads (R-Smads: Smad1, Smad2, Smad3, Smad5, Smad8, and Smad9). (2) Common partner Smads (Co-Smad: Smad4) that provide R-Smads with DNA binding properties. (3) Inhibitory Smads (I-Smads: Smad6 and Smad7) [5]. Upon the stimulation of BMPs ligand, R-Smads are phosphorylated by the serine/threonine kinase of the type I receptor and forms a heteromeric complex with the Co-Smad, Smad4. The complex is then translocated into the nucleus to regulate the transcription of target genes in conjunction with other nuclear cofactors, such as osteocalcin (BGP) and bone alkaline phosphatase (BALP). BGP and BALP are marker genes of cell viability and differentiation of osteoblast. I-Smads interfere with the type I receptor activation of R-Smads, thus hindering the assembly of R-Smads with Co-Smad. Although the downstream signaling of the BMP-2/Smad pathway leading to osteoblast differentiation has been extensively investigated, the changes of Smads remain poorly understood.

Human osteosarcoma Saos-2 cells have been shown to contain extractable bone-inducing agents that possess osteoblastic properties known for inducing differentiation $[6,7]$. Recent findings from molecular studies suggest that BMPs differ from other osteogenic compounds. Many signaling pathways with diverse functions have been found to play a role in BMP/Smads-mediated osteogenesis. Several of these pathways are also critical in the differentiation of other cell lineages, including chondrocytes and osteoblasts. Although fluoride has been known to affect bone cells, relatively little is known about the specific mechanisms responsible for these effects. This study aims to summarize our current knowledge of BMP/Smads-mediated osteogenesis by presenting recently completed work which may help us to further elucidate the mechanisms of fluoride-induced Saos-2 cells differentiation.

\section{Materials and Methods}

\section{Cell Culture and Conditioned Medium}

The human osteoblast-like cell line (Saos-2) was obtained from the American Type Culture Collection, derived from a human osteosarcoma $[8,9]$. The cell line used in the study were maintained in IMDM and RPMI-1640 (Hyclone Laboratories, Beijing, China) medium supplemented with $10 \%$ fetal bovine serum and penicillin/streptomycin mixture (100 $\mathrm{U} / \mathrm{mL}$ penicillin $\mathrm{G}, 100 \mu \mathrm{g} / \mathrm{mL}$ streptomycin sulfate; Hyclone
Laboratories, Beijing, China) at $37^{\circ} \mathrm{C}$ in a humidified atmosphere of $95 \%$ air and $5 \% \mathrm{CO}_{2}$. After a 36-h attachment, cells were grown to $80 \%$ confluence, and the medium was replaced with serum-free medium and then various doses of $\mathrm{NaF}$ were added.

\section{Cell Proliferation}

Saos- 2 cells were seeded into 96-well flat-bottomed plates at a density of $5 \times 10^{3}$ cells/well, and then incubated with $0,0.1,0.2$, $0.4,0.8$, and $1.6 \mathrm{mM} \mathrm{NaF}$ for 24,48 , and $72 \mathrm{~h}$. Cell proliferation was determined using WST- 8 dye (Cell Counting Kit-8/ CCK-8, Beyotime, Jiangsu, China) according to manufacturer's instructions. After $10 \mu \mathrm{L}$ WST- 8 dye was added to each well, cells were incubated at $37{ }^{\circ} \mathrm{C}$ for $2 \mathrm{~h}$ and the absorbance was measured at $450 \mathrm{~nm}$ using a microplate reader (Bio-Rad, Hercules, USA). The experiment was repeated six times, and the mean value was calculated for each $\mathrm{NaF}$ concentration.

\section{Quantitative Real-Time PCR}

Saos-2 cells were exposed to NaF, and total RNA was isolated using a Fast Pure RNAKit (Takara Bio, Shiga, Japan) according to the manufacturer's instructions. For reverse transcription reaction, cDNA was synthesized from total RNA (1.0 $\mu \mathrm{g} /$ reaction $)$ using Reverse Transcription kit (Promega, Madison, USA) at $42{ }^{\circ} \mathrm{C}$ for $60 \mathrm{~min}$ and then $95^{\circ} \mathrm{C}$ for $10 \mathrm{~min}$. Quantitative realtime PCR (Q-PCR) was performed in a total reaction volume of $20 \mu \mathrm{L}$ with an Real Master Mix (SYBR Green) kit (Tiangen Biotech, Beijing, China) per well using $1.0 \mu \mathrm{L}$ of cDNA template and the appropriate primer for the target genes and normalized to glyceraldehyde-3-phosphate dehydrogenase (GAPDH). The primer sequences and annealing temperatures are shown in Table 1. Q-PCR amplifications were performed in a capped 8-well optical plate. The reaction conditions were as follows: 2 min at $95^{\circ} \mathrm{C}, 40$ cycles of $20 \mathrm{~s}$ at $95^{\circ} \mathrm{C}$, and $10 \mathrm{~s}$ at $68^{\circ} \mathrm{C}$. Fluorescence of the gene specific Q-PCR products was continuously measured and used for quantitative purposes. At the end of the amplification period, melting curve analysis was performed to confirm the specificity of the amplicon. Relative quantification of gene expression was calculated by using $2^{-\Delta \Delta \mathrm{CT}}$ equation. All data derived using Q-PCR was from multiple experiments with at least triplicate independent biological samples.

\section{Immunofluorescence}

The cells exposed to $\mathrm{NaF}$ for $72 \mathrm{~h}$ were fixed with $4 \%$ paraformaldehyde for $30 \mathrm{~min}$. They were then permeabilized in PBS $/ 0.2 \%$ Triton X-100 for 10 min and blocked with $3 \%$ bovine serum albumin in PBS for $30 \mathrm{~min}$. The cells were then incubated with primary antibodies overnight. Mouse monoclonal anti-Smad1 antibody (Abcam, Cambridge, UK) and phosphorylated rabbit polyclonal anti-Smad1/5 antibody (Cell 
Table 1 RT-qPCR primers for gene expression analysis

\begin{tabular}{llll}
\hline Primer & GenBank accession no. & Sequence $\left(5^{\prime}-3^{\prime}\right)$ & Annealing temperature $\left({ }^{\circ} \mathrm{C}\right)$ \\
\hline BALP & NM_000478.4 & F:CATCCTGTATGGCAATGGG & 56 \\
& & R:CATCCTGTATGGCAATGGG & \\
BGP & NM_199173.3 & $\begin{array}{l}\text { F:AGGGCAGCGAGGTAGTGA } \\
\text { R:CCTGAAAGCCGATGTGGT }\end{array}$ & 57 \\
& & F:CCATCATAACAGCACTACC & 55 \\
Smad4 & NM_005359.5 & R:CGTATCCATCAACAGTAACA & \\
& & F:GGATTTGGTCGTATTGG & 56 \\
GAPDH & NM_002046.3 & R:GGAAGATGGTGATGGGATT & \\
& &
\end{tabular}

Signaling Technology Inc., Danvers, USA) mixed together were used at 1:50, Mouse monoclonal anti-Smad5 antibody (Abcam, Cambridge, UK) and phosphorylated rabbit polyclonal anti-Smad1/5 antibody(Cell Signaling Technology Inc., Danvers, USA) mixed together was used at 1:50, rabbit polyclonal anti-Smad4 antibody (Cell Signaling Technology Inc., Danvers, USA) was used at 1:50. Cells were washed three times in PBS and then stained with the mixed secondary antibodies for $60 \mathrm{~min}$. DayLight 405-conjugated goat anti mouse antibody (1:100; EarthOx Biotech Inc., San Francisco, USA) and Cy3conjugated goat anti rabbit antibody (1:200; Beyotime, Jiangsu, China) were mixed together. FITC-conjugated goat anti rabbit antibody (Boster Biotech Inc., Wuhan, China) was used at 1:60. The expression and locations of Smads in Saos-2 cells were observed using a C1 plus (Nikon Corp., Tokyo, Japan) lasers scanning confocal microscope and processed using Adobe Photoshop.

\section{ShRNA and Transfection}

Four pairs of green fluorescent protein (GFP)-labeled shRNA targeting Smad4 corresponding to the respective coding regions were designed and synthesized by custom-made plasmid vectors (GenePharma Corp., Shanghai, China) and used according to the manufacturer's protocols. The nonsense sequence with no similar match to any known sequence was used as control. The Smad4-shRNA1 sequence: CTGCCAACTTT CCCAACAT; the Smad4-shRNA2 sequence: GCCTCCCATT TCCAATCAT; the Smad4-shRNA3 sequence: CGGTCTTTG TACAGAGTTA), and the nonsense sequence to Smad4 was named negative control shRNA (NC-shRNA: GGTGTGCAG TTGGAATGTA). All shRNA sequences were compared against human sequences deposited in GenBank ${ }^{\mathrm{TM}}$ databases with BLAST (Basic Local Alignment Search Tool) searches using the NCBI (National Center for Biotechnology Information) tools. Plasmid stocks were titrated by infection in Saos-2 cells and assessed by GFP fluorescence. For shRNA experiments, Saos-2 cells were grown overnight in 6-well plates. Cells were transfected with $20 \mathrm{ng} / \mathrm{ul}$ of shRNA using X-tremeGENE HP DNA $^{\text {TM }}$ (Roche Diagnostics GmbH, Mannheim, Germany) as instructed by the manufacturer. After transfection, Smad4 suppression was analyzed by Q-PCR to confirm gene knockdown. Treatment with fluoride, the expression of BGP and BALP were determined after Smad4-shRNA transfection.
Fig. 1 Growth curve of fluoridetreated Saos- 2 cells. Saos- 2 cells were seeded into 96-well plates and cultured with different concentrations of $\mathrm{NaF}$ for 24,48 , and $72 \mathrm{~h}$ as indicated in the "Materials and Methods." The WST assay was performed to quantify the cytotoxicity of fluoride to Saos-2 cells. Asterisk indicate the significant differences

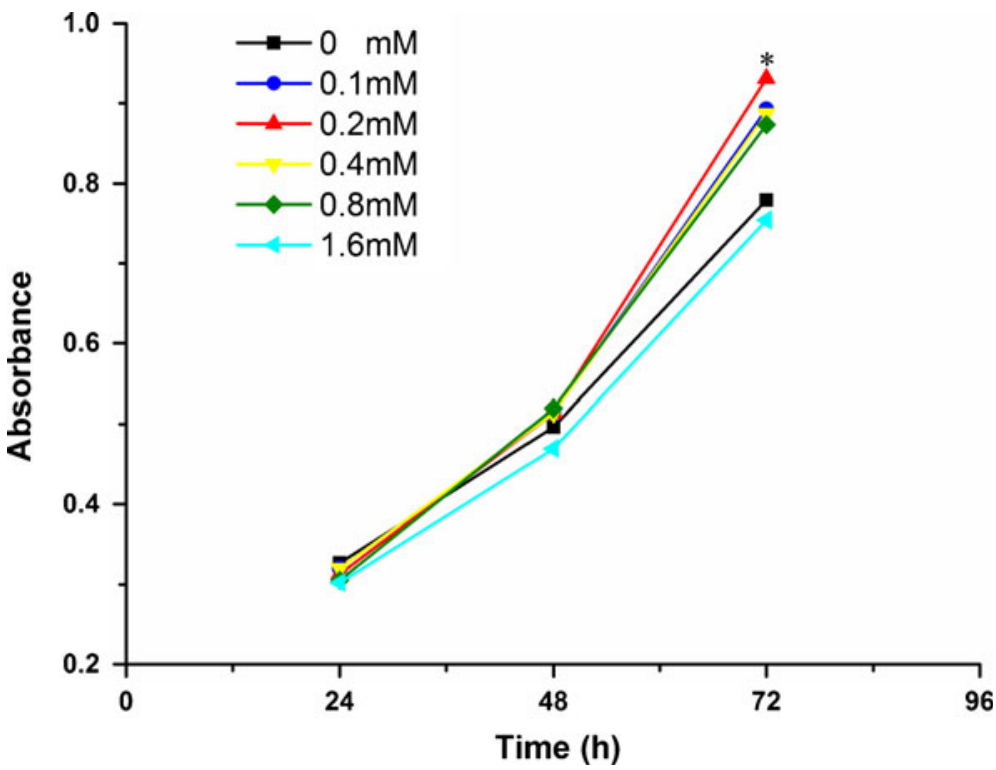


Fig. 2 Quantitative RT-PCR results of BALP and BGP mRNA in fluoride-treated Saos-2 cells. Saos- 2 cells were treated with $\mathrm{NaF}$ over $72 \mathrm{~h}$ and subjected to real-time RT-PCR analysis using specific primers. Expression was quantified by the $2-\Delta \Delta \mathrm{CT}$ method. Gene expression was determined in triplicate, normalized with GAPDH, and is graphed relative to expression. ${ }^{*} P<0.05$, compared with the control group

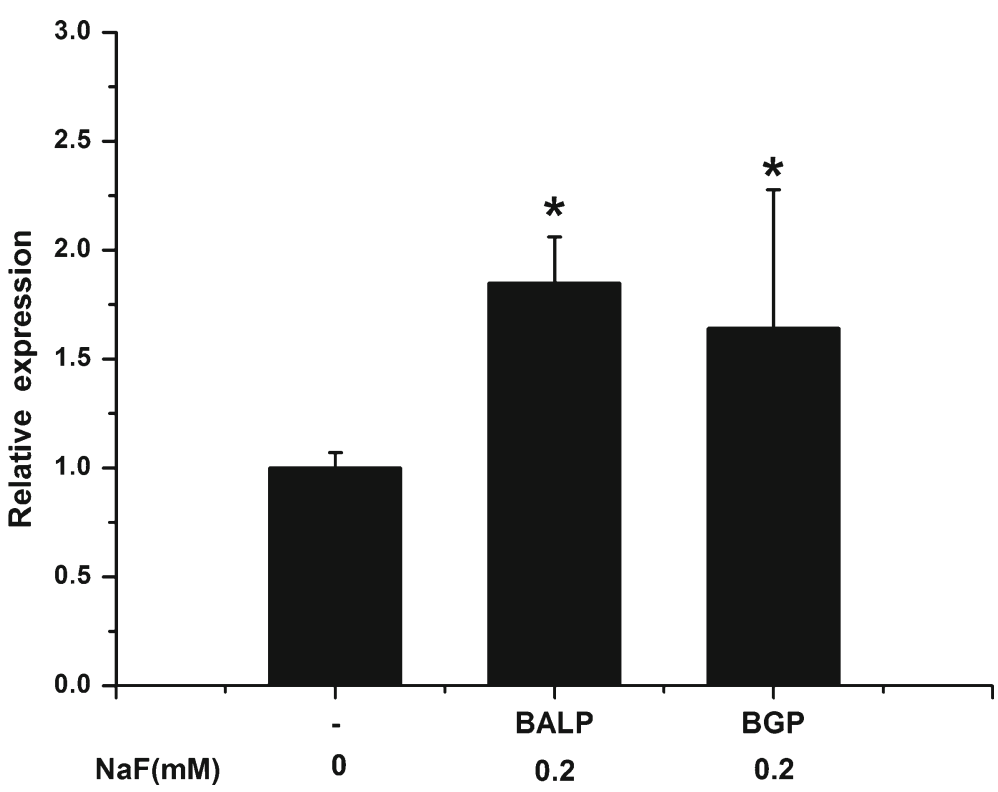

SPSS 13.0 (SPSS Inc., Chicago, IL, USA) software. Values of $P<0.05$ were considered significant.

\section{Results}

As shown in Fig. 1, the survival rates of Saos-2 cell increased as fluoride concentration increased at both 48 and $72 \mathrm{~h}$ posttreatment with fluoride, except at 1.6 mM. Moreover, Saos-2
Fig. 3 Content of Smad1 and $\mathrm{p}$-Smad $1 / 5$ protein in fluoridetreated Saos-2 cells. Laser scanning confocal microscopy was used to detect expression of Smad 1 and $\mathrm{p}-\mathrm{Smad} 1 / 5$ proteins after exposure to $\mathrm{NaF}(200 \times)$. a, c Control $(0 \mathrm{mM} \mathrm{NaF})$ and $\mathbf{b}, \mathbf{d}$ $0.2 \mathrm{mM}$ NaF groups; a, b Smad1 and $\mathbf{c}, \mathbf{d}$ p-Smad1/5. Three wells were assayed for each experimental treatment, and three separate experiments were performed
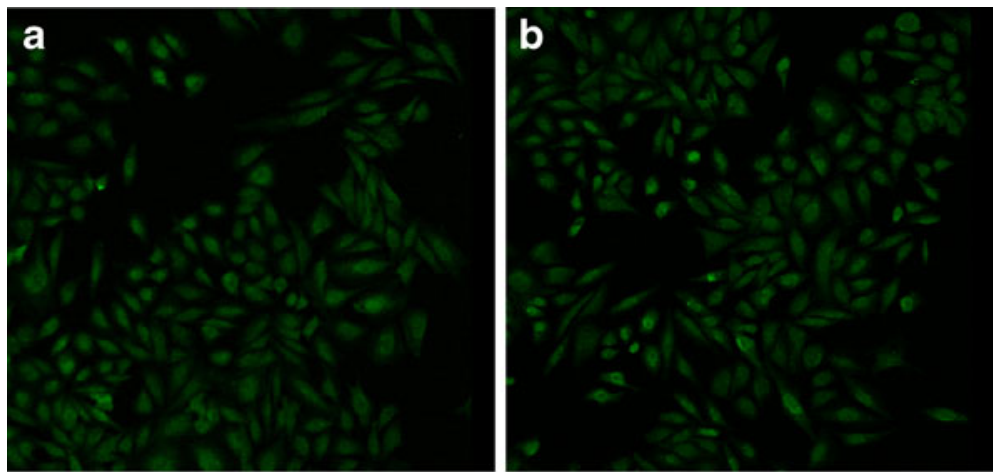

\section{C}

d 
Fig. 4 Content of Smad5 and pSmad1/5 protein in fluoridetreated Saos-2 cells. Laser scanning confocal microscopy was used to detect expression of Smad5 and $\mathrm{p}-\mathrm{Smad} 1 / 5$ proteins after exposure to $\mathrm{NaF}(200 \times)$. a, c Control $(0 \mathrm{mM} \mathrm{NaF})$ and $\mathbf{b}, \mathbf{d}$ $0.2 \mathrm{mM} \mathrm{NaF}$ groups; a, b Smad5 and $\mathbf{c}, \mathbf{d ~ p}$-Smad1/5. Three wells were assayed for each experimental treatment, and three separate experiments were performed
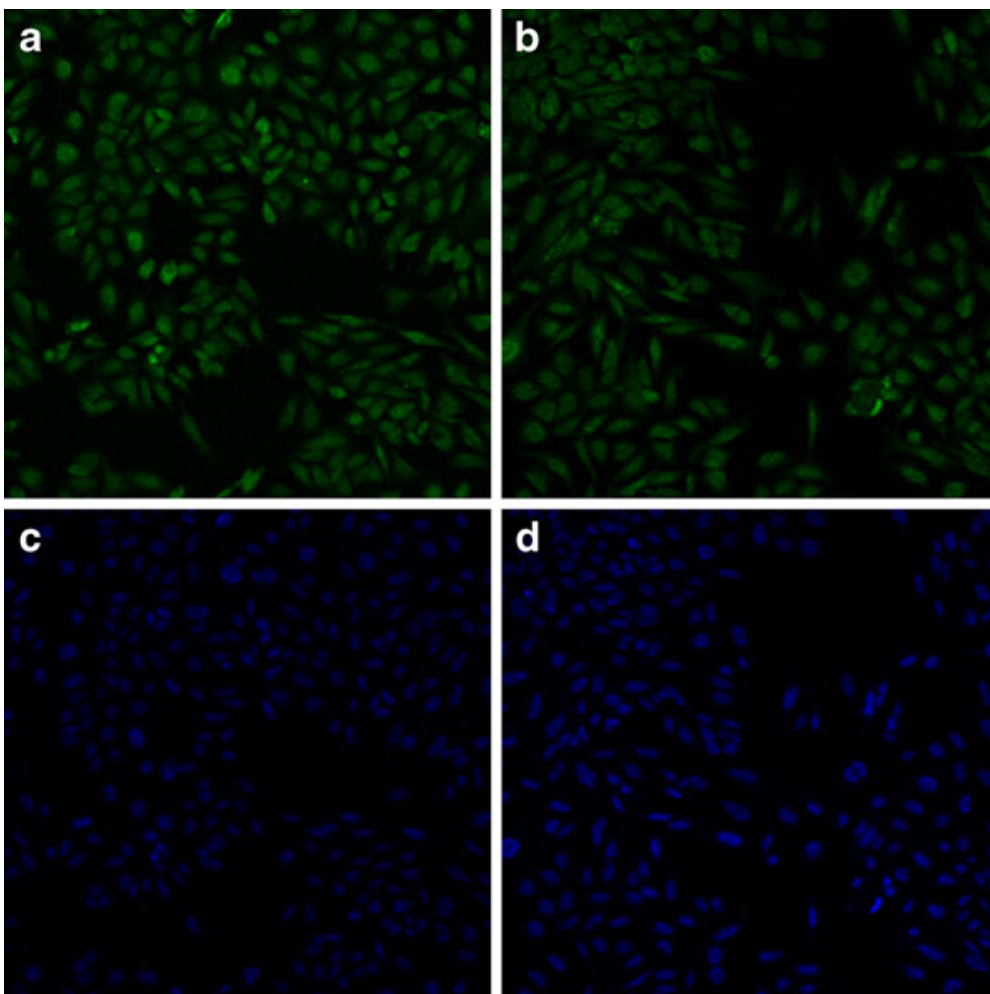

cells with $0.2 \mathrm{mM}$ fluoride over $72 \mathrm{~h}$ exhibited significantly higher level of proliferation compared with other concentrations. Thus, fluoride-induced Saos-2 cell osteoblast marker genes expression was examined at the concentration of $0.2 \mathrm{mM}$ fluoride for $72 \mathrm{~h}$

Subsequently, we found that treatment with fluoride enhanced the expression of BGP and BALP, the early markers of osteoblast differentiation, compared with the control group (Fig. 2). These results demonstrate that fluoride at a dose of $0.2 \mathrm{mM}$ promotes the osteoblastic differentiation of Saos-2 cells.

We further found that Smad1, Smad5, and p-Smad1/5 were present in the cytoplasm and nucleus of Saos-2 cells (Figs. 3 and 4), and Smad4 exhibited that nuclear accumulation upon stimulation with $0.2 \mathrm{mM}$ fluoride, compared with the control group (0 mM NaF) (Fig. 5). Upon NaF stimulation, both R-
Smads accumulated in the cytoplasm and nucleus of Saos-2 cells (Figs. 3b and $4 b$ ), which was not significantly elevated compared with the control group (Figs. 3a and 4a). Likewise, Smad4 was not significantly changed after stimulation by $0.2 \mathrm{mM}$ fluoride (Fig. 5b). Therefore, fluoride did not significantly change the protein level of total R-Smads and CoSmad, but the levels of R-Smad phosphorylation significantly increased (Figs. 3c, d and 4c, d).

Finally, we detected if Smad4 silencing abrogates fluorideinduced Saos- 2 cells differentiation, shRNAs were designed to target on the human Smad4 mRNA (Fig. 6a). The RNAi efficiency in Saos-2 cells was evaluated by RT-qPCR. The Smad4 shRNA1, shRNA2, and shRNA3, which targeted different Smad4 cDNA sequences respectively, reduced the levels of Smad4 mRNA expression, with shRNA3 being more effective than others (Fig. 6b), but the expression of Smad4 was not

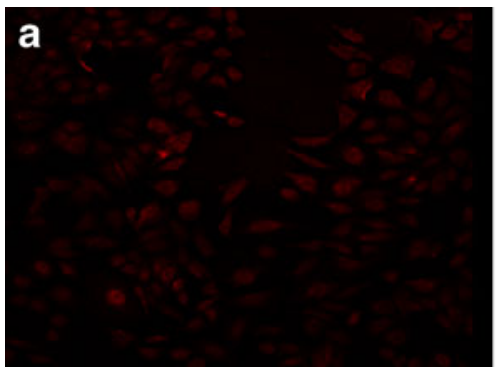

Fig. 5 Content of Smad4 protein in fluoride-treated Saos-2 cells. Laser scanning confocal microscopy was used to detect expression of Smad4 proteins after exposure to $\mathrm{NaF}(200 \times)$. a Control $(0 \mathrm{mM} \mathrm{NaF})$ and $\mathbf{b}$

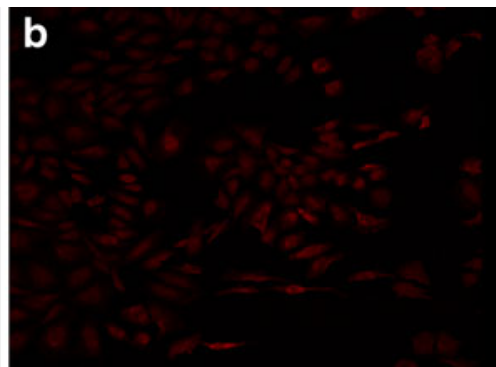

$0.2 \mathrm{mM} \mathrm{NaF}$ groups. Three wells were assayed for each experimental treatment, and three separate experiments were performed 
Fig. 6 Effects of shRNAs against Smad4 mRNA. a Transfection efficiency of Smad4-shRNA observed by laser scanning confocal microscopy $(200 \times)$; b quantitative RT-PCR showing expression of Smad4 mRNA in Saos-2 cells following infection with shRNA1,2,3 and mismatch shRNA. Gene expression was determined in triplicate, normalized with GAPDH and is graphed relative to expression. $* P<0.05$, compared with the control group a
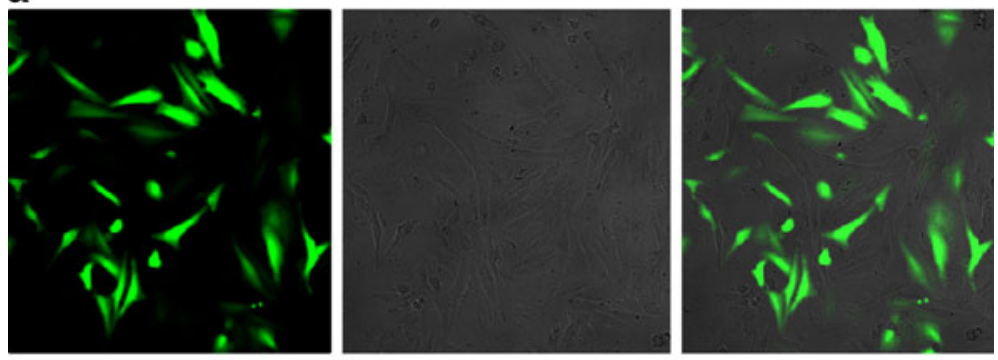

b

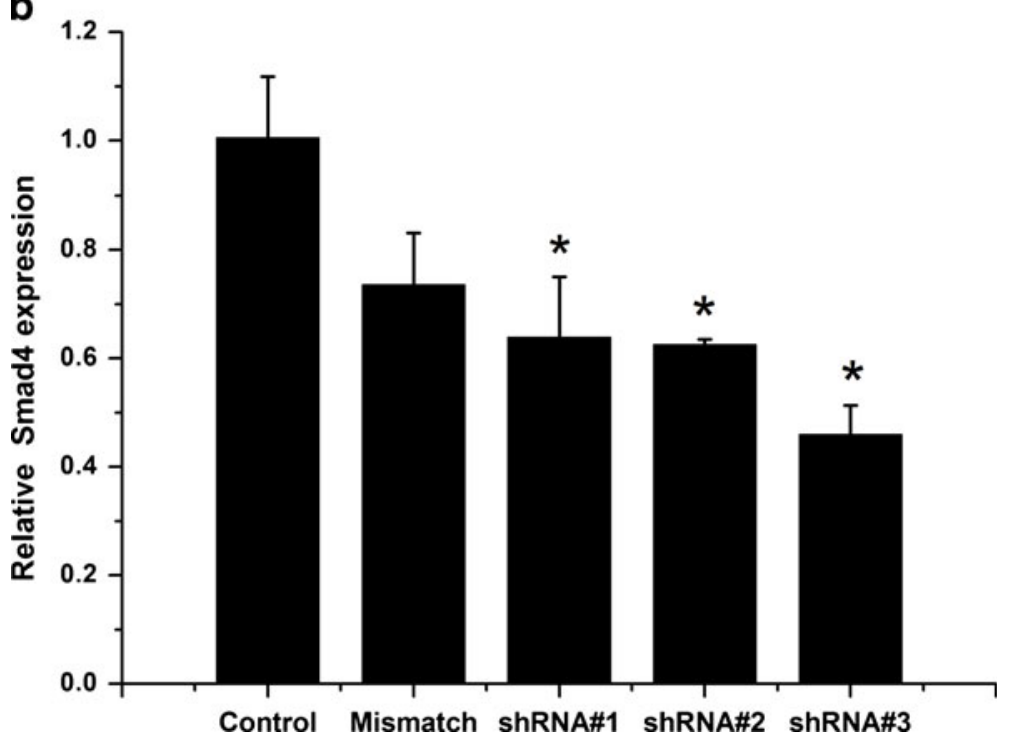

remarkably suppressed by mismatch shRNA interference at the mRNA level (Fig. 6b). Given that the RNAi effect by shRNA3 was found to be the most reproducible, shRNA3 was used for the subsequent RNAi experiments. As shown in Fig. 7, treatment with fluoride enhanced the expression of BGP and BALP compared with the control group, whereas blocking $\mathrm{BMP} / \mathrm{Smad}$ signaling inhibited the upregulated expression of BGP and BALP induced by fluoride, suggesting that inhibition of the BMP/Smad signaling interrupts fluoride-induced Saos-2 cells differentiation.
Fig. 7 Inhibition of BMP/Smad signaling inhibits fluorideinduced Saos- 2 cells differentiation. Gene expression was determined by quantitative RT-PCR, normalized to GAPDH expression, and is graphed relative to the expression. $* P<0.05$, compared with the control group; $\# P<0.05$, compared with the group only treated with fluoride

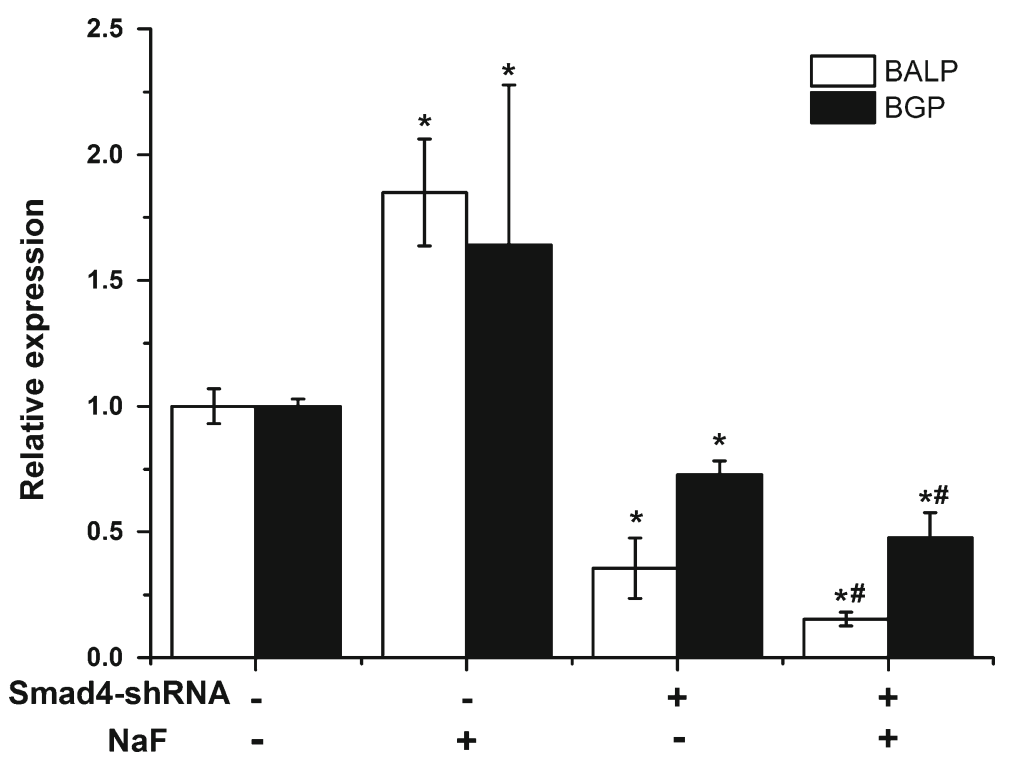




\section{Discussion}

BMP signaling plays a significant role in osteoblast differentiation. However, how BMP/Smads signaling drive transdifferentiation for osteoblasts differentiation remains unclear. In this study, we found that fluoride significantly enhanced the proliferation of Saos- 2 cells, which is consistent with the findings of Lau and Baylink [10], that BMP/Smad signaling becomes activated in Saos-2 cells during their differentiation, and that the activation of Smads during Saos-2 cells differentiation was due to phosphorylation of R-Smads, rather than enhancement in total R-Smads and Co-Smad.

Emerging evidence indicates that fluoride acts directly on cells of the osteoblast lineage to promote their development and/or activity. Okamoto et al. showed that increased BMP4 signaling in vivo stimulated osteoblast [11]. Chen et al. showed that a peak expression for type I collagen occurred in the early phase (day 1) of fetal rat calvarial osteoblasts [12]. BGP is the most abundant noncollagenous protein in bone and is present in the bone matrix and synthesized by osteoblasts [13, 14]. Van Straalen et al. showed that bone-alkaline phosphatase is a useful parameter for monitoring changes in bone formation [15]. Accumulation of these bioactive molecules in vitro could potentially induce proliferation and differentiation of osteoblasts and result in the formation of new bone [16]. In our present study of Saos-2 cells, the expression of two markers for osteoblastic differentiation-BGP and BALP mRNAs - were significantly increased by fluoride. The expression of BALP and BGP were higher in the fluoride group than the control group. However, the expression of BGP was not significantly increased as the expression of BALP (Fig. 2). This led us to assume that BALP is more sensitive in monitoring osteoblast-like Saos-2 cells formation and differentiation.

BMP signals through the type II receptor, encoded by different genes in combination with the type I receptors [17-19]. The type I receptors, BMP-RIA and BMP-RIB, have been shown to stimulate osteoblastic differentiation in preosteoblastic cell lines [20]. Some scholars indicated that $\mathrm{C} 2 \mathrm{C} 12$ myoblasts can be induced to express some early osteoblast markers in response to elevated BMP signaling [21, 22]; however, this stimulation was inadequate for osteoblast differentiation. BMPs form a unique group of proteins within the transforming growth factor- $\beta$ super-family and have a pivotal role in the regulation of bone induction, maintenance and repair [23, 24]. BMPs stimulate the activation of Smad proteins that accumulate in the nucleus and control the transcription of a large number of target genes. Smad1, Smad5, and Smad8 are recognized by BMP type I receptor, which play important roles in osteoblast differentiation [24]. Smad1 and Smad5 have been shown to be the major signaling molecules for inducing differentiation of $\mathrm{C} 2 \mathrm{C} 12$ cells into osteoblasts [25]. Several studies have shown that Smad1/5/ 8 could form heteromeric complexes with Co-Smad Smad 4 and translocate into the nucleus where they regulate transcription of various target genes [26]. In our study, we found that phosphorylations of Smad1/5 are equally enhanced in fluoride-treated Saos-2 cells; however, there is very little difference between fluoride-treated and control cultures in total Smad1 and Smad5, which demonstrates that an activation of fluoride-induced Saos2 cells differentiation was due to dephosphorylation of Smad1 and Smad5, rather than enhanced expression of total Smad1 and Smad5. The role of Smad4 in the phases of osteoblastdifferentiating process remains unclear. In the present study, fluoride had no effect on the protein level of Smad4. It is possible that partially functional Smad4 interacted with phosphorylationed Smad1/5 to form hetero-oligomeric complexes which translocate into the nucleus to regulate the transcription of various target genes, as the total level of Smad4 have not significantly change.

Taken together, we demonstrated that fluoride induces Saos2 cells differentiation in parallel with the phosphorylations of Smad1/5, which then mediated differentiation via activation of Smad signaling. We therefore conclude that the BMP/Smad pathway plays a role in fluoride-induced differentiation of Saos-2 cells.

Acknowledgments This work was supported by grants from the National Natural Science Foundation of China (grant numbers: 30800956 and 81172605).

Open Access This article is distributed under the terms of the Creative Commons Attribution License which permits any use, distribution, and reproduction in any medium, provided the original author(s) and the source are credited.

\section{References}

1. Ripamonti U, Teare J, Petit JC (2006) Pleiotropism of bone morphogenetic proteins: from bone induction to cementogenesis and periodontal ligament regeneration. J Int Acad Periodontol 8:23-32

2. Bruserud O, Tronstad KJ, Berge R (2005) In vitro culture of human osteosarcoma cell lines: a comparison of functional characteristics for cell lines cultured in medium without and with fetal calf serum. J Cancer Res Clin Oncol 131:377-384

3. Subramaniam S (2002) Bioinformatics of cellular signalling. Novartis Found Symp 247:104-252

4. Reddi AH (1998) Role of morphogenetic proteins in skeletal tissue engineering and regeneration. Nat Biotechnol 16:247-252

5. Kretzschmar M, Massague J (1998) SMADs: mediators and regulators of TGF-beta signaling. Curr Opin Genet Dev 8:103-111

6. Mitsui N, Suzuki N, Maeno M, Yanagisawa M, Koyama Y, Otsuka K, Shimizu N (2006) Optimal compressive force induces bone formation via increasing bone morphogenetic proteins production and decreasing their antagonists production by Saos-2 cells. Life Sci 78:2697-2706

7. Degasne I, Basle MF, Demais V, Hure G, Lesourd M, Grolleau B, Mercier L, Chappard D (1999) Effects of roughness, fibronectin and vitronectin on attachment, spreading, and proliferation of human osteoblast-like cells (Saos-2) on titanium surfaces. Calcif Tissue Int 64:499-507 
8. Kanno T, Takahashi T, Tsujisawa T, Ariyoshi W, Nishihara T (2005) Platelet-rich plasma enhances human osteoblast-like cell proliferation and differentiation. J Oral Maxillofac Surg 63:362-369

9. Postiglione L, Domenico GD, Montagnani S, Spigna GD, Salzano S, Castaldo C, Ramaglia L, Sbordone L, Rossi G (2003) Granulocytemacrophage colony-stimulating factor (GM-CSF) induces the osteoblastic differentiation of the human osteosarcoma cell line SaOS-2. Calcif Tissue Int 72:85-97

10. Lau KH, Baylink DJ (2003) Osteoblastic tartrate-resistant acid phosphatase: its potential role in the molecular mechanism of osteogenic action of fluoride. J Bone Miner Res 18:1897-1900

11. Okamoto M, Murai J, Yoshikawa H, Tsumaki N (2006) Bone morphogenetic proteins in bone stimulate osteoclasts and osteoblasts during bone development. J Bone Miner Res 21:1022-1033

12. Chen L, Scholler J, Foged NT (1997) Effects of progesterone on proliferation and differentiation of fetal rat calvarial osteoblasts in vitro. Zhonghua Fu Chan Ke Za Zhi 32:538-540

13. Price PA (1989) Gla-containing proteins of bone. Connect Tissue Res 21(51-57):57-60

14. Price PA, Williamson MK (1985) Primary structure of bovine matrix Gla protein, a new vitamin K-dependent bone protein. J Biol Chem 260:14971-14975

15. van Straalen JP, Sanders E, Prummel MF, Sanders GT (1991) Bonealkaline phosphatase as indicator of bone formation. Clin Chim Acta 201:27-33

16. Iwata T, Morotome Y, Tanabe T, Fukae M, Ishikawa I, Oida S (2002) Noggin blocks osteoinductive activity of porcine enamel extracts. J Dent Res 81:387-391

17. Rosenzweig BL, Imamura T, Okadome T, Cox GN, Yamashita H, Ten DP, Heldin CH, Miyazono K (1995) Cloning and characterization of a human type II receptor for bone morphogenetic proteins. Proc Natl Acad Sci U S A 92:7632-7636
18. Ten DP, Yamashita H, Ichijo H, Franzen P, Laiho M, Miyazono K, Heldin CH (1994) Characterization of type I receptors for transforming growth factor-beta and activin. Science 264:101104

19. Ten DP, Franzen P, Yamashita H, Ichijo H, Heldin CH, Miyazono K (1994) Serine/threonine kinase receptors. Prog Growth Factor Res 5:55-72

20. Ishidou Y, Kitajima I, Obama H, Maruyama I, Murata F, Imamura T, Yamada N, Ten DP, Miyazono K, Sakou T (1995) Enhanced expression of type I receptors for bone morphogenetic proteins during bone formation. J Bone Miner Res 10:1651-1659

21. Aoki H, Fujii M, Imamura T, Yagi K, Takehara K, Kato M, Miyazono K (2001) Synergistic effects of different bone morphogenetic protein type I receptors on alkaline phosphatase induction. J Cell Sci 114:1483-1489

22. Katagiri T, Akiyama S, Namiki M, Komaki M, Yamaguchi A, Rosen V, Wozney JM, Fujisawa-Sehara A, Suda T (1997) Bone morphogenetic protein-2 inhibits terminal differentiation of myogenic cells by suppressing the transcriptional activity of MyoD and myogenin. Exp Cell Res 230:342-351

23. Nohe A, Keating E, Knaus P, Petersen NO (2004) Signal transduction of bone morphogenetic protein receptors. Cell Signal 16:291-299

24. Sykaras N, Opperman LA (2003) Bone morphogenetic proteins (BMPs): how do they function and what can they offer the clinician? J Oral Sci 45:57-73

25. Fujii M, Takeda K, Imamura T, Aoki H, Sampath TK, Enomoto S, Kawabata M, Kato M, Ichijo H, Miyazono K (1999) Roles of bone morphogenetic protein type I receptors and Smad proteins in osteoblast and chondroblast differentiation. Mol Biol Cell 10:38013813

26. Wan M, Cao X (2005) BMP signaling in skeletal development. Biochem Biophys Res Commun 328:651-657 